\title{
WHY DO WE DEAL WITH THE ECONOMICS OF INNOVATION IN SUCH AN UNCERTAIN PERIOD AT THE GLOBAL LEVEL?
}

\author{
Prof dr Petar Đukić \\ Editor-in-Chief of Economics, Innovative and Economics Research Journal
}

\section{Editorial}

\section{INCEPTION}

The world today is burdened with a number of war zones, threats of war, and partially with cold war, as well. Paris Climate Agreement (after the USA quit it), as well as the European Union (after Brexit), could also be quit by other participants or members. Hence, where does the motivation to deal with new economy based on innovations and knowledge come from?

\section{DEPICTION OF GLOBAL ECONOMY}

Bearing in mind the complexness of the moment, it may be the best to start from the fact that global economy is currently growing at the rate of (3.7\%), which is slightly higher compared to expectations declared six months ago. Projections for upcoming years are cautiously optimistic. Intending to implement the idea of organising a conference on the following topic "New Economy 2018 - Innovations, Reforms and Modern Business", which will be held here in Bijeljina, in the heart of West Balkan, on 24-th of May 2018, at this uncertain and unfavourable moment internationally; we started from the approach that a hope for renewal of cooperative international political scene should always exist and be maintained, in order to encourage innovative technological and economic collaboration worldwide.

This should make room for social synergy which would then lead to a number of particular actions to be taken in order to create conditions for comprehensive and inclusive growth as long-term and fundamental betterment for a large part of the planet. It is much more difficult to propose particular actions for making one incentive ambient for the competition of innovations, as oppose to the competition of strategies of geo-political and military impact and domination.

Still, the will for that should never be lost. Any desire for improving the situation is at the same time encouragement for innovations. They are an endless resource of growth and development, as well as of international long-term collaboration. The works published in this Issue have been intended for the international conference. Furthermore, some of the participants from distant countries will contribute to this through Skype, one of the paradigm innovations, which has rapidly become common technology and global public good. However, in this case, the most important issue is to present a topic which is inspiring enough for such broad participation.

\section{INNOVATION CONTROVERSIES OF THE WORLD TODAY}

Innovative economy simply appears as a flawless concept, as well as a solution without precedent in the world today. However, it is not exactly the case. Anything occurring at the global scene, which 
is relevant to reconfiguration of global power, by its definition interferes with interests of people, relative status of families, social classes, nations and regions. Therefore, a number of controversies and reluctance appear as a rule. Global innovative economy nowadays has been facing some serious challenges, as follows:

1. Institutions and innovations. Innovation can be of a spontaneous nature, but current global experience has shown that institutionalisation of an innovative process simply implies. Moreover, without firm and stable institutions, an innovation frequently shows and then disappears before long. Ownership rights, protection of intellectual property, the right to a patent, etc., are all epochal achievements of the civilisation, which could easily collapse if the Law is not obeyed and if informal, customary or extractive institutions over rule, since they exhaust economic effects and aggregate the benefit from institutions inappropriately;

2. Risks to innovations and necessity of adjustment. Many innovations appear rather frequently, but they cannot be controlled in the same manner as it was the case in the past. Therefore, an institutional network is to be built to facilitate adjustment to innovations, especially of participants in labour market, as well as of many professions, businesses and work methods which undergo relevant and essential changes. Another significant risk to innovations is potential technology manipulation, along with a misuse of the power of technology in a number of fields. This is not about cybercrime only, but about risks to the environment and biodiversity as well, or to human health and safety (GMO);

3. Inequality. Innovations accelerate social differentiation and increase inequality. This issue is to be dealt with by future economy and society worldwide, as well as by processes included in innovative economy. The world today is more strictly divided into the $1 \%$ of the powerful and 99\% of powerless ones, which has been proven in studies made by researchers of inequality, out of that two Nobel Prize laureates (Stiglitz - the USA, and Piketty - France) and equally good Serbian researcher of global inequalities Branko Milanović of the World Bank. Control of inequality and risks pertaining to above mentioned ratio, will be one of key challenges of new economy and even of the innovation policies.

4. Incentives to innovations - innovation bureaucracy. What is the benefit of introducing economic policies in the innovation sector? Does the policy of allocating incentives to the rapidly growing IT sector create the effect of unnecessary feeding someone who is already full? What will happen to differences between the most advance sector and the other ones which are less innovativeintensive? Could innovations be influenced by bad, extractive institutions (Robbins, Acemoglu) in addition to good (inclusive) ones? These questions require socially responsible and professionally founded responses.

5. Social and political contents of innovations. In addition to technical innovations, pure economic, market, organisational (entrepreneur), specific social and cultural innovations are present as well, and they are not to be neglected. What is their long-term social impact; to what extent do positive externalities of innovations overlap; and who is responsible for negative externalities? What are intergeneration and moral consequences of innovations; what is their ideological impact on political values and objectives?

There is no much speculation there on in the theory or practice of innovation. The responses will probably be found spontaneously through practice. But is this sufficient?

\section{INNOVATION POLICIES: INCENTIVES, CONTROL AND CAUTION}

People should not be indifferent to ever-growing waves of potential innovations or to new economy in general. As a matter of fact, fascism emerged from a number of social innovations which were used by extreme ideologists and leaders to have attracted followers through very pragmatic measures. They were to a large extent similar to acceptable social innovations such as: social care, 
public work, solidarity, collective assistance and self-help. IT viruses and cybercrime, which are present today, had emerged spontaneously as an innovation and so called "business", but they have "exploded" as a technology risk number one of the modern world.

One social fact should be doubtless: innovations are an integral part of the dynamic economic reality, and there are no structural changes or encouraging technological advancement without them. Most of the world's nations currently need a more dynamic growth above all, to contribute to social betterment, with elements of humane and inclusive development. Cardinal structural changes arising from new technological solutions, innovations and new economy contribute to this growth to the largest extent.

However, this does not mean that a spontaneous development without social, environmental or moral control of technology advancement is what we need as a whole. Besides, scientific research and innovations offered in medical science, including genetic engineering, manipulation with genome or potential cloning of human and other structures are very disputable morally and hard to be accepted from social point of view.

Inclusiveness in development is frequently defined as the potential of growth, which provides for a permanent decrease of poverty, controls social and environmental balance; saves resources and energy, contributes to employment and minimises inequality, causes a positive effect to climate changes, and makes the society more humane. All of these are very difficult to achieve at the same time, but they are worth trying. A policy which would strategically shape new innovative economy moving towards humane, socially balanced and environmentally sustainable development, requires permanent reconsideration and redefining, for the very purpose of continuity of useful and good innovations.

Innovation must be and should remain the means of achieving an objective and an initiator of cardinal social changes, but only if it is under the institutional, legal and democratic control of the society, i.e. its existing and future social consequences should be put under control.

\section{CAN BUSINESS EXIST WITHOUT INNOVATIONS AND REFORMS?}

It certainly can. Only, there is the issue of the level of development and social-economic progress which can be achieved thanks to innovations. However, the most important part of the response to the question asked in the heading depends on objectives and orientation of the society and economy, including macro-economic goals, regional or developmental ones, as well as microeconomic goals which consider more deeply the meaning of categories such as the following: reforms, entrepreneurship and technological changes.

Economies today mainly do not function as aggregate of activities performed by all of the economic subjects, traditionally taken as enterprises and households. Interconnection at the horizontal, vertical, geo-strategic or global levels is the inevitability which new technologies bring. This does not mean that there are no more small, traditional or single economic entities. Even if they do exist, they are at the margins of the new economics structure worldwide, known as new economy. This is good news for small companies and small nations. A number of local communities within underdeveloped societies, even with medium and lower income, have shown a high level of capacities for innovations and use thereof, based on both high and medium-level technologies. Key contribution to development of new economy based on knowledge and innovations can be expected from those small and medium economies. The world as a whole is expected to make more room for innovations which lead to humane and inclusive development, protection of people and nature, and less for any form of destruction.

Jun 2018.

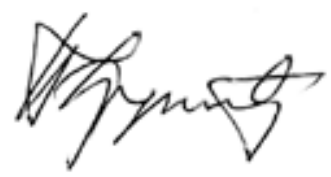

